\title{
Benefits, challenges, and perceptions of the multiple article dissertation format in instructional technology
}

\author{
Rebecca Arlene Thomas, Richard E. West, Peter Rich \\ Brigham Young University
}

\begin{abstract}
This study used survey data to investigate the benefits, challenges, perceptions, and current practices of the multiple article dissertation format in instructional technology. Online surveys were sent to current students, alumni, faculty, and department representatives of instructional technology programs, and data were analysed using qualitative and quantitative methods. The surveys found that alumni who completed multiple article format dissertations received more citations for their dissertations than those who completed traditional dissertations, showing that the multiple article format can increase the likelihood of impact. Additionally, respondents reported that multiple article dissertation formats facilitate authenticity and collaboration and prepare students for a career in academia. However, some participants perceived the multiple article format to be less rigorous than traditional dissertations, with ambiguous requirements and expectations of quality. More research is needed in order to understand current practices for multiple article dissertation formats in instructional technology.
\end{abstract}

Even though doctoral degrees have been awarded since the end of the 13th century (McClelland, 1980), the numbers of students pursuing and earning $\mathrm{PhDs}$ have grown significantly over the past century. During the 20th century, numbers of PhDs awarded in the United States grew from a low of $293 \mathrm{PhDs}$ awarded in 1902 (Thurgood, Golladay, \& Hill, 2006), to 49,562 PhDs awarded in 2009 (Fiegener, 2010). This increase of PhDs awarded in the United States reflects similar growth in $\mathrm{PhD}$ attainment internationally. For example, the first PhD awarded in Australia was in 1948, and as of 2009, 31,140 students were enrolled in Australian PhD programs (Evans, Macauley, Pearson, \& Tregenza, 2009).

As more students are earning $\mathrm{PhDs}$ and writing dissertations, criticisms of the traditional dissertation format have surfaced (Duke \& Beck, 1999). Most scholars agree that the main purposes of the dissertation are to train students in proper research methodology and to contribute original findings to research (Isaac, Quinlan, \& Walker, 1992; Yoels, 1973). However, some worry that the traditional dissertation format is not conducive to either of these goals. Research has shown that dissertations rarely get disseminated into academic journals (De Jong, Moser, \& Hall, 2005; McPhie, 1960; Robinson \& Dracup, 2008), and that academics rarely cite dissertations that have not been published into articles (Yoels, 1973). Additionally, some scholars argue that the traditional dissertation format is a poor training tool because it does not prepare scholars for future professional pursuits (Duke \& Beck, 1999; Tronsgard, 1963).

In an attempt to overcome the limitations of the traditional dissertation format, some instructional technology programs have implemented alternative culminating projects for $\mathrm{PhD}$ students. However, little research has been done on the overall perceptions of these alternative projects within the field. This research attempts to fill that gap by using qualitative and quantitative survey data to answer the following research questions:

(1) What are the perceived benefits and challenges to students, faculty, and institutions of completing alternative culminating projects such as the multiple article format?

(2) What current practices are there for completing and mentoring a multiple article format dissertation?

\section{Literature review}

In this literature review, we will give a brief history of the dissertation, discuss the purposes of the dissertation, and address literature regarding advantages and disadvantages of the multiple article dissertation format. 


\section{History of the dissertation}

From this review of the literature, the history and purposes of the dissertation, and doctoral education, became apparent. At the end of the 13th century, German scholars merged research and teaching in universities, creating the first doctoral degrees (McClelland, 1980). As these studies developed, culminating projects for PhDs evolved from oral lectures to published dissertations by the mid-18th century (Breimer, Janssen, \& Damen, 2005; McClelland, 1980). A century later, Americans visited Germany, and were inspired to duplicate the German educational tradition in America (Duke \& Beck, 1999; Fox, McMillan, \& Eaton, 1999). As a result, the first American PhD was awarded by Yale University in 1861 (Wolfle \& Kidd, 1971). It wasn't until the 20th century that countries outside of Germany and the United States started regularly requiring doctoral students to complete dissertations (Willis, Inman, \& Valenti, 2010).

\section{Purposes of the dissertation and concerns}

Since its origin, the dissertation has had several purposes (Berelson, 1960; Gilman, 1974; Tronsgard, 1963). When it first originated, the main purposes of the dissertation were to train young scholars in proper research methodology and to contribute original findings to research. Although most scholars agree that these are still purposes of the dissertation today (Isaac et al., 1992; Yoels, 1973), some argue that the dissertation is more of a training tool than it is a contribution to the field (Berelson, 1960; Breimer, Janssen, \& Damen, 2005; Gilman, 1974), because dissertations are rarely disseminated in academic journals (De Jong et al., 2005; Duke \& Beck, 1999; Gross, Alhusen, \& Jennings, 2012; McPhie, 1960; Morris \& Tipples, 1998; Robinson \& Dracup, 2008). Very few dissertations get cited in academic publications (Yoels, 1973), and the majority of dissertations never get published into academic articles or books (De Jong et al., 2005; McPhie, 1960; Robinson \& Dracup, 2008).

\section{Lack of dissemination}

Traditional dissertations in education consist of five extensive chapters that explain a single research study: introduction, literature review, methods, results, and conclusions (Calabrese, 2006). Critiques of the traditional dissertation format have two main concerns: dissemination and authenticity. Research on percentages of dissertations disseminated is sparse, but some work has been done. For example, McPhie (1960) sampled 385 dissertations from 54 universities and colleges completed in social studies education in 1934-1957. Of about $75 \%$ of those dissertations, publication data were available. Almost two-thirds were never published as articles, and over $93 \%$ never became book chapters. Although some argue that a dissertation should lend itself to several academic articles (Boeckmann \& Porter, 1982), the reality is that it is difficult for students to publish after graduation (Morris \& Tipples, 1998; Robinson \& Dracup, 2008; Tronsgard, 1963). Since dissertations are often written differently from academic articles, most dissertations have to be revised and rewritten in order to be suitable for publication (Duke \& Beck, 1999). It is common for recent graduates of $\mathrm{PhD}$ programs to get a timeconsuming job and lose motivation to rewrite their dissertation for publication (Robinson \& Dracup, 2008; Tronsgard, 1963). Often, dissertation results become outdated if a $\mathrm{PhD}$ waits too long to publish.

\section{Lack of authenticity}

The second main critique of the traditional dissertation format is that the process of completing a traditional dissertation is different from the process of completing research post-graduation (Tronsgard, 1963), meaning that writing a traditional dissertation may not authentically prepare students for work post-graduation. The traditional dissertation requires a thorough account of the research completed (Reid, 1978; Robinson \& Dracup, 2008), including a literature review covering everything related to the topic of investigation, complicated statistics and design, and extensive conclusions (Gilman, 1974). Due to length requirements for journals, academic articles are much shorter than dissertations, and therefore, require shorter literature reviews, methods, and discussion sections. Although an academic will write many academic articles through his or her career, he or she will only write one dissertation (Duke \& Beck, 1999). Critics of the traditional dissertation argue that a scholar will never have to do research in the amount of depth a dissertation requires after receiving a doctorate degree (Duke \& Beck, 1999). However, others argue that the in-depth experience is necessary for a complete 
knowledge of the field (Lee, 2010) and worry that shorter literature reviews will result in a loss of expertise (Boote \& Beile, 2005).

The traditional dissertation also lacks authenticity for $\mathrm{PhDs}$ who plan to work outside of research and academia. For example, students who plan to go into practical fields may see minimal personal relevance in the traditional dissertation (Boeckmann \& Porter, 1982), especially because it is unlikely to be disseminated to practising professionals (De Jong et al., 2005; Gross et al., 2012; Morris \& Tipples, 1998; Robinson \& Dracup, 2008). Additionally, the process of the traditional dissertation is different from most practical work. Most educational practitioners work in teams, while the dissertation tends to be a solo endeavour (Monaghan, 1989; Tronsgard, 1963). The traditional dissertation's apparent lack of authenticity could be a reason why many students want to avoid research after graduation (Gilman, 1974), and why the dissertation is the main reason many doctoral students aren't awarded PhDs (Gilman, 1974; Tronsgard, 1963).

\section{Alternative culminating projects}

In an attempt to overcome the limitations of the traditional dissertation, some programs in higher education have approved an alternative culminating project for $\mathrm{PhD}$ students (Archbald, 2010; Lee, 2010), which is defined as a required project completed at the end of a $\mathrm{PhD}$ that differs from the traditional five chapter dissertation. In the field of instructional technology, the most common alternative culminating project is the multiple article format. Although requirements vary by institution, the multiple article format requires students to complete multiple research studies, written as articles ready for publication. This format addresses the two main concerns of the traditional dissertation, dissemination and authenticity, for several reasons. First, it makes dissemination easier because the articles are ready for journal submission (Gross et al., 2012; Morris \& Tipples, 1998; Walkington \& Jenkins, 2008). Second, the process of writing the articles is authentic to academic research. Students who complete a multiple article format dissertation gain experience in writing for an audience outside their institution (Duke \& Beck, 1999; Hartley \& Betts, 2009; Hill, Kneale, Nicholson, Waddington, \& Ray, 2011; McPhie, 1960; Morris \& Tipples, 1998; Robinson \& Dracup, 2008; Walkington, 2008) and gain experience in publication, which is part of the entire research experience (Robinson \& Dracup, 2008; Walkington \& Jenkins, 2008).

\section{Multiple article format advantages}

The multiple article format has other advantages to the traditional dissertation as well. Since this format makes dissemination less time-consuming, and requires students to do multiple research studies, students often publish more prior to graduation. These publications can be advantageous for both students and their advisors. Although students with publications upon graduation tend to have better employment options and salary (De Jong et al., 2005; Hartley \& Betts, 2009; McPhie, 1960; Robinson \& Dracup, 2008; Walkington, 2008) and a foundation for a research career (De Jong et al., 2005; Morris \& Tipples, 1998), advisors are often co-authors on the publications, which can increase their job security and tenure (De Jong et al., 2005; Hartley \& Betts, 2009; Gross et al., 2012; Robinson \& Dracup, 2008).

Additionally, the multiple article format can present a psychological advantage to students. Some students find this format less stressful, as it breaks one large dissertation into smaller projects (De Jong et al., 2005). Also, students tend to find writing articles to be more motivating and feel rewarded with a sense of confidence and accomplishment upon publication (Charlesworth \& Foster, 1996; De Jong et al., 2005).

\section{Multiple article format disadvantages}

Even though it has several advantages, the multiple article format also has disadvantages and critiques. One main concern is the issue of depth. Since articles are shorter than traditional dissertations, publications tend to have shorter literature reviews, methods sections, and conclusions (Reid, 1978). Many worry that students need the in-depth research experience a dissertation provides in order to fully understand academic research (Lee, 2010; Robinson \& Dracup, 2008). In response to the issue of depth, some programs require students to include appendices to the dissertation, with expansion on the literature reviews, methods, and conclusions in the articles (Thomas, Nelson, \& Magill, 1986). 
Another issue with the multiple article format in education is lack of familiarity (Morris \& Tipples, 1998). Considering most education professors completed a traditional dissertation themselves, some find it difficult to mentor a student completing an alternative culminating project. Additionally, some professors may want their students to have the same dissertation experience as they did (Tronsgard, 1963). If university faculty are unfamiliar with the multiple article format, they may be wary of its implementation.

Initial implementation of the multiple article format has also called for changes in practice. For example, most universities store dissertations of graduates in an open access section of the library. When articles get published, the journal owns the copyright (Breimer et al., 2005). In order to publish multiple article format dissertations with traditional dissertations, some universities solve this problem by publishing alternate versions of the published articles (Baggs, 2011). Similarly, other practical changes in response to the multiple article format include, but are not limited to, issues of authorship order in articles (Gross et al., 2012) and the tendency to selfplagiarise in multiple articles (Robinson \& Dracup, 2008). Each concern that arises with the implementation of the multiple article format calls for adaptability within the structure of the institution.

Even with all the adaptations made to address the concerns and critiques above, acceptance of the multiple article format in education has been slow (Morris \& Tipples, 1998), as it was when biology first implemented the multiple article format (Reid, 1978). With time, biologists have progressively become more accepting and accommodating of the multiple article format, and now it has become mainstream in the hard sciences (Monaghan, 1989). With time and effort, many education professors have reported that the multiple article format appreciation grows (Morris \& Tipples, 1998; Reid, 1978). Because of this debate over the merits of this alternative culminating project, many questions remain about its acceptance in instructional technology, as well as the perceptions of students and faculty who have completed one.

\section{Instructional technology and the current study}

Instructional technology in particular may be poised to take advantage of multiple article format dissertations because it is a practitioner field that aims to produce research that impacts practitioners as well as scholars (Anglin, 1995; Seels \& Richey, 1994). Since the majority of traditional dissertations don't get published in academic journals (De Jong et al., 2005; Duke \& Beck, 1999; Gross et al., 2012; McPhie, 1960; Morris \& Tipples, 1998; Robinson \& Dracup, 2008), practitioners are more likely to benefit from published articles. However, as yet, no study has measured the acceptance of the multiple article format in the field of instructional technology. Understanding this can help students make informed decisions when planning dissertations and can help faculty advise students in different dissertation formats. Additionally, the knowledge of different perspectives can help administrators who wish to implement multiple article format dissertations in their institutions.

\section{Methods}

This research used a mixed-methods approach, in order to capitalise on the strengths of both qualitative and quantitative survey items. Johnson and Onwuegbuzie (2004) stated that a mixed methods approach "can answer a broader and more complete range of research questions because the researcher is not confined to a single method or approach" (p. 21).

Additionally, Morse (1991) posited that methodological triangulation often involves determining which method is given dominant status. Since this research is primarily interpretive in nature, an emphasis was placed on qualitative methods, which were used to investigate the usefulness, benefits, and challenges of multiple article dissertation formats. Quantitative measures were simultaneously used to supplement qualitative findings by reporting tendencies, patterns, and differences between groups. In order to provide convenience and confidentiality to participants, we used an online survey to collect both qualitative and quantitative data from students, alumni, faculty, and department representatives of instructional technology (and similar) programs. 


\section{Participant sampling}

We wanted to understand the perspectives of students, alumni, and department representatives from instructional technology and similar programs. Students included respondents who were enrolled in instructional technology $\mathrm{PhD}$ programs at the time of administration. Alumni included respondents who had graduated from instructional technology $\mathrm{PhD}$ programs at the time of administration. These included faculty members and practitioners. Department representatives included faculty members who were in a position of leadership in the instructional technology department they were a part of, such as department heads. Only one department representative was surveyed from each department.

To identify instructional technology programs, we first used the 161 programs identified in the Educational Media and Technology Yearbook (Orey, 2013). After we identified the programs, we sent links of the surveys to the department representatives listed and requested their participation. In addition, we requested that department representatives send surveys to their faculty, graduates, and current students. To recruit additional participation, notices were posted to educational technology professional communities and networks such as ITFORUM and the Facebook/email groups for the Association of Educational Communications Technology (AECT) and Professors of Instructional Design Technology organisations. The survey and research methods were approved through our university's institutional review board and administered in January, 2014. Seventythree students, 43 alumni, and 12 department representatives responded.

Although we did our best to recruit enough participants to represent the field internationally by circulating the survey through social media and professional web forums, almost all of our participants were based out of the USA, and therefore, the responses reflect the Germanic-style $\mathrm{PhD}$. Therefore, our participant sampling is a main limitation of this research.

\section{Instruments}

We administered two different online surveys, one for students and alumni and one for department representatives.

Student and alumni surveys asked about types of dissertation formats available as options, their preferences towards certain dissertation formats, and a rationale for their preferences. In addition, alumni surveys asked additional questions about their current professions, publications from dissertations, and perceptions of how their chosen dissertation formats affected their educational experience. For example, some items asked about the time it took alumni to complete a PhD, and other items asked about the quality of the mentoring they received on their dissertation.

Department representative surveys included all items contained in the alumni survey. These items were pooled with the remaining alumni data and were included in all analyses specific to alumni. In addition to alumni questions, department representative surveys asked representatives about their institution's available dissertation formats, followed by a rationale for those decisions. If respondents indicated that their institutions provided multiple article format dissertations, questions were asked about challenges they have faced, ways they have overcome such challenges, and perceived benefits of the decision to implement multiple article dissertation formats.

Additionally, all respondents were asked basic demographic questions, along with perceived advantages and disadvantages of the multiple article format. Since these questions were given to all respondents, findings for these themes were reported as a conglomeration, with specifications of different perceptions highlighted between groups.

\section{Data analysis}

Quantitative items were analysed using both inferential and descriptive statistics. A chi-square test of independence was used for inferential statistics. Respondents were stratified according to their occupational 
role following graduation (professor vs practitioner), along with the year in which they completed their PhD (2009 and before vs 2010 and later). We then compared participation in these groupings with dissertation format preference.

Qualitative data were initially analysed using an emergent coding scheme, in order to establish categories following preliminary examination of responses (Stemler, 2001). Categories generated were used to identify perceptions of the advantages and disadvantages of the multiple article format and to describe the types of policies and expectations required of those completing multiple article format dissertations. After the lead researcher developed categories for each qualitative survey item, the categories were reviewed by two senior researchers. Once agreement on categories was established, codes were established by "themeing the data" [sic] in order to deduce the meanings in each category (Saldaña, 2012, pp. 139-145). "Themeing the data" was chosen because qualitative survey responses often implied themes without explicitly stating them. For example, one respondent may respond to the question, "Why did you choose to do multiple article dissertation?" by typing "Publications." Although the original category for this code would be Publication, the meaning of this code could be Perception that the completion of a multiple article dissertation will yield a greater number of publications. The process of "themeing the data" put responses into context and gave them meaning, so researchers could draw implications. Throughout the process of "themeing the data," the lead researcher developed codes and discussed the codes with two senior researchers. Codes were revised until all three researchers reached a consensus. All data were coded using an Excel spreadsheet.

Concerning the reporting of findings, themes supported by five or more participants were included in the results section. Since the major thrust of this research was qualitative, quantitative data were included if they supported or contradicted qualitative findings.

\section{Trustworthiness}

Regarding the qualitative survey responses, several measures of trustworthiness were used. During the data analysis, the lead researcher generated 70 codes under 11 categories. Following the original coding, the lead researcher consulted with two senior researchers and incorporated their feedback. Once the coding was complete, the lead researcher condensed the original codes into the 15 codes under seven categories discussed in the paper (see Figure 1).

Following data analysis, we conducted two trustworthiness techniques as described by Lincoln (1985). First, the lead researcher met with a senior qualitative researcher who was not part of the research team to conduct an inquiry audit. Second, the lead researcher conducted a negative case analysis, and the few negative cases found were incorporated into the results throughout the paper. In an additional effort to ensure trustworthiness, the researchers made the data available to participants in aggregate form and welcomed their feedback. 


\section{Categories and Codes}
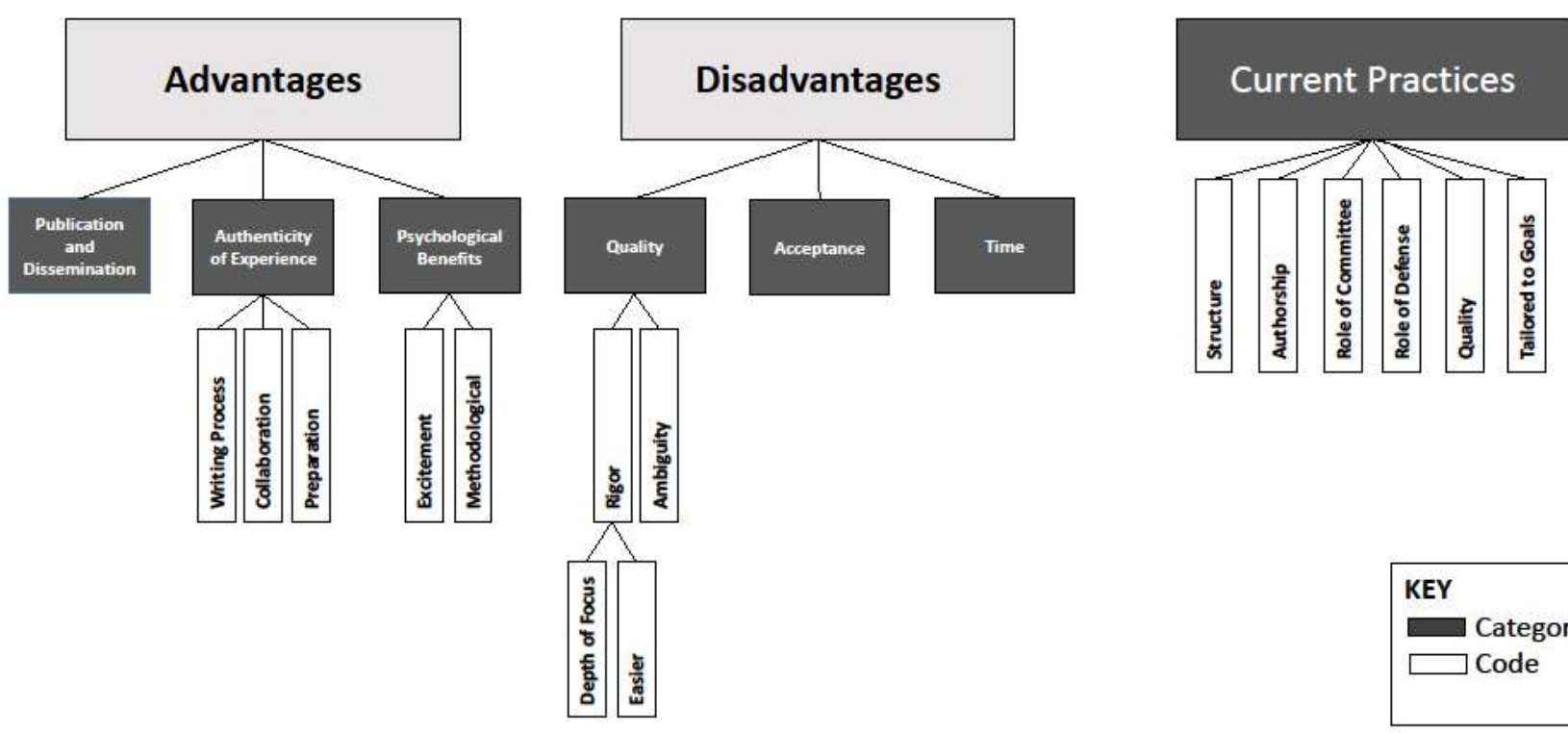

Figure 1. Coding tree for final categories and codes. The dark grey boxes contain the seven overall categories, while the white boxes contain the 15 codes below them.

\section{Results}

The following are findings related to dissertation format preferences, perceived advantages and disadvantages of multiple article dissertation formats, and current practices of multiple article formats in instructional technology programs. Following in Table 1, we provide descriptive statistics that indicate alumni and department representative perceptions. 
Table 1

Descriptive statistics

\begin{tabular}{|c|c|c|}
\hline Group & Questions & Responses \\
\hline \multirow[t]{16}{*}{ Alumni $(N=43)$} & What dissertation format would & Traditional format (8) \\
\hline & you recommend to another & Alternative culminating experience (35) \\
\hline & student? & Multiple article format (16) \\
\hline & & Hybrid (10) \\
\hline & & Other (9) \\
\hline & If you completed an alternative & Delayed (2) \\
\hline & culminating project, did doing so & Expedited (1) \\
\hline & $\begin{array}{l}\text { delay or expedite your } \\
\text { graduation? }\end{array}$ & No difference (same) (6) \\
\hline & What dissertation format do you & Traditional format is more work (7) \\
\hline & believe requires more work? & Both formats are the same amount of work (21) \\
\hline & & Multiple article format is more work (15) \\
\hline & If any, how many articles have & No publications (25) \\
\hline & been published from your & One publication (13) \\
\hline & dissertation? & Three publications (2) \\
\hline & & Four publications (2) \\
\hline & & Five publications (1) \\
\hline \multirow{4}{*}{$\begin{array}{l}\text { Department } \\
\text { representatives } \\
(N=12)\end{array}$} & \multirow{4}{*}{$\begin{array}{l}\text { Which format(s) does your } \\
\text { program currently support for } \\
\text { granting doctoral dissertations? }\end{array}$} & Traditional format (12) \\
\hline & & Alternative culminating experience (5) \\
\hline & & Multiple article format (5) \\
\hline & & Hybrid (3) \\
\hline
\end{tabular}

\section{Dissertation format preferences}

Although student preferences leaned slightly towards traditional dissertation formats, many students favoured alternative culminating projects. When asked what dissertation format they would choose to complete, 11 out of 24 students who had not begun working on their dissertation stated they would prefer an alternative culminating project. Of the 13 students who were currently working on their dissertation, 9 students were completing traditional dissertations, while 3 were completing multiple article dissertations. One student was completing a hybrid dissertation format, which is defined as a culminating project that includes components of both the traditional dissertation format and the multiple article format.

Alumni preferences skewed in favour of alternative culminating projects. Even though $70 \%$ of alumni surveyed completed a dissertation in a traditional format, only 8 of them recommended a traditional format to other students (see Table 1). The remaining 35 alumni recommended that students complete some kind of alternative culminating project, with 16 recommending a multiple article format, 10 recommending a hybrid format, and 9 recommending other. Alumni showed no significant difference in recommendation based on career choice (professor vs practitioner), $\chi(1, n=43)=0.072, p=.788$, or the year in which they graduated (2009 and before vs 2010 and later) $\chi(1, n=43)=1.651, p=.199$.

\section{Perceived benefits of multiple article format}

Students and alumni identified several benefits of multiple article dissertation formats, most of which fall under the following themes: publication and dissemination, authenticity of experience, and psychological benefits. 


\section{Publication and dissemination}

Respondents across all survey groupings perceived the multiple article format to be a supportive format for publication and dissemination. Students surveyed felt that having publications when they graduate could give them additional opportunities to attend conferences and be a part of discussions in the field. Alumni shared similar views, and added that writing articles while in graduate school gives students the opportunity to get feedback on their work from readers outside their institution, resulting in collaboration and integration within the academic community.

Additionally, students who preferred the multiple article format expressed a desire for their research to be heard, and felt that their findings would go unnoticed if left unpublished. As one student put it, "I would rather write something that has a chance to be read by more than my committee and my mom." Although traditional dissertations can be published as articles, students appreciated that multiple article dissertation formats have the potential to cut down or eliminate rewriting prior to journal submission.

Alumni self-reported publication statistics also support the argument that multiple article dissertation formats could lead to more publication and dissemination. For example, a higher percentage of alumni who completed multiple article or hybrid dissertations reported publishing their dissertation; with $60 \%$ (8 out of 13) of alumni who completed alternative culminating projects reporting publications, compared to the $37 \%$ (10 out of 26) of alumni who completed traditional dissertations. However, further research is needed on this statistic because of the relatively small sample sizes.

When asked to list citations of both their original dissertations and articles from their dissertations, 25 out of 43 of our respondents did not list any publications (for more details, see Table 1). Of alumni who did list publications, the number of citations from alternative culminating projects outweighed the number of citations from traditional dissertations, with traditional dissertations having an average of 2.63 citations, and alternative culminating projects an average of 6.33 citations. This indicates that articles from multiple article format dissertations create more impact than traditional dissertations that are not published into articles. Considering the majority of alumni surveyed did not publish their dissertation, the multiple article format has the potential to increase research impact in the field.

\section{Authenticity of experience}

Students and alumni agreed that multiple article dissertation formats can provide students with authentic experiences that prepare students for work beyond graduate education. In particular, students and alumni thought that the multiple article format could lead to authentic experiences in writing process, collaboration, and career preparation.

(1) Writing process. A major theme for students and alumni was the perception that multiple article dissertation formats provide students with authentic experience in writing for academic journals. This benefit was seen as particularly useful for students who plan to go into academia, with two alumni recommending multiple article dissertation formats for academics and traditional dissertations for practitioners. Participants suggested that writing articles as part of the dissertation can teach students the entire process of academic publication, from the writing style to the process of journal submission and review. Alumni especially noted that articles require a different writing style than traditional dissertations, and that writing for journals is a skill that requires development. As one alumni put it:

The dissertation allows you to really get into and wrap your head around the data, and allows your committee to see the thought process. However, nowhere else in the scholarly community do we write like this. And what is a PhDs purpose but to write and teach others through their writing? Clarity and brevity are essential. Just because you can write a dissertation does NOT mean you can write and get published. 
Overall, this was a major theme, as 29 alumni asserted that the most authentic way to prepare a student for a publish-or-perish world is practice in writing publishable manuscripts.

(2) Collaboration. Participants noted that writing articles can give students additional opportunities to collaborate with advisors and committee members. Although 6 out of 9 alumni who completed alternative culminating projects reported that they received the same amount of mentoring from their advisors as they would have doing a traditional dissertation, the alumni who reported that they received more mentoring ( 3 out of 9 alumni) sensed that their advisors were more invested in mentoring their dissertations because they knew they would be published.

Students and alumni also added that completing alternative culminating projects led to collaboration with committee members after the defence. Comments of this nature ranged from advisors mentoring students as they published their manuscripts to additional research being conducted with committee members after students graduated. Although this collaboration could occur regardless of dissertation format, students attributed the authenticity of multiple article format dissertations to the increased collaboration they experienced with their committee members.

(3) Preparation for a career. In addition to authenticity in writing process and collaboration, students communicated the idea that multiple article dissertation formats could prepare them for future careers in academia. Specifically, students felt that having publications could assist them in obtaining jobs, starting research agendas, and hastening their tenure process. Although students saw the value in the traditional dissertation, they saw multiple article dissertation formats as a more efficient way to learn how to do research while strengthening their curriculum vitae. Alumni highlighted the importance of publication in the academic world. To illustrate this, one department representative related:

Most doctoral students will, in my experience, end up teaching in higher ed[ucation]. Therefore they are in a publish or perish world. So if they can get a couple of articles out of their dissertations, they have a leg up for promotion and tenure. We did not have that option years ago. I wish I had.

Overall, students and alumni agreed that having articles could give a good start to their careers by building students' resumes and providing students a base for research agendas.

\section{Psychological benefits}

In synchronicity with the literature, respondents identified several psychological benefits of multiple article dissertation formats. Department representatives observed that students experience an increased level of excitement at the thought of getting published, and that this excitement motivates them as they progress. In conjunction with this, one student completing a traditional dissertation perceived that alternative culminating projects may lead to faster progress and stated:

In watching a colleague going through the alternative process at the University of Idaho I have a high degree of envy that he seems to be making much faster progress as he is taking on the entire process in a more modular or incremental fashion.

Similarly, students completing the multiple article format appreciated its incremental fashion and suggested that it can make the dissertation more manageable.

\section{Perceived disadvantages of the multiple article format}

Along with benefits, students and alumni also identified perceived disadvantages of multiple article dissertation formats, most of which fall under the following themes: quality, acceptance, and time. 
Quality

Participants from all demographic groups worried that the quality of multiple article dissertations may be lower than traditional dissertations. Specifically, respondents commented on rigor and ambiguity of requirements.

(1) Rigor. A common concern among students and alumni who preferred the traditional dissertation format was a perceived lack of rigor involved in the multiple article format. Although some respondents felt that length requirements for articles inhibit thorough explanation of literature reviews and methods sections, others identified concerns that additional appendices could not easily fix. Alumni especially noted that the structure of the multiple article format broadens the scope of a student's dissertation research. They argued that if students are completing multiple studies, they will not develop enough focus on one topic to experience the level of depth that the traditional dissertation format leads to. This led to concerns that the multiple article format may lead to a more shallow understanding of the research process.

(2) Ambiguity of requirements. Responses of department representatives were most telling as to the ambiguity of judging alternative culminating projects. Of the institutions surveyed that offer the multiple article format, four out of five departments reported that they had no defined expectation of quality for the articles written. This could be why five students and alumni who completed multiple article dissertations felt unsure as to what was expected of them. When talking about multiple article formats at their institution, one student said, "Because it isn't as common, there are not as many models/examples out there for me to look to for guidance." On the other hand, it seems that some institutions have quality examples of multiple article formats, as one department representative stated the reason that their institution has continued to offer the multiple article format is because of "high quality examples that have made it (multiple article format) stick as an option." Although it could be that some institutions are working on defining expectations, the quality of current multiple article dissertations being completed at most institutions is unclear.

\section{Acceptance}

Participants in all demographic groups perceived a lack of acceptance of alternative culminating projects. For example, one current student said, "I have heard that some people don't look at alternative-format dissertations as being as credible or in-depth as traditional." Along these lines, four students and alumni worried that employers might look down on alternative culminating projects. Althugh one department representative voiced this view, five representatives perceived a lack of acceptance among other professors. Some institutions that did not offer the multiple article format, but had considered it, said that voices of opposition from both within their departments and within other areas of their institutions prevented multiple article dissertations from being implemented. Although this supports the idea that alternative culminating projects are not completely accepted in academia, no support was given for the perception that employers in other professional areas reject multiple article dissertations.

\section{Time}

When asked about the challenges of the multiple article format, students and alumni perceived them to be more time-consuming than traditional dissertation formats. This perception was supported by quantitative data (see Table 1). Out of the nine alumni surveyed who completed an alternative culminating project, two claimed that doing so delayed graduation, while only one claimed that the multiple article format expedited graduation. However, the majority (six respondents) reported that the multiple article format took the same amount of time as a traditional format.

Alumni perceptions of workload skew towards the multiple article format being more work (see Table 1), with seven out of 43 alumni seeing traditional dissertations as more work, 21 alumni seeing the workload to be equal for both dissertation formats, and 15 alumni seeing the multiple article format as more work.

In conjunction with alumni perceptions, two department representatives reported that students tend to take longer completing the multiple article format, while three department representatives didn't see any difference 
in the time required to complete traditional multiple article dissertations. Overall, perceptions of time lean slightly towards multiple article formats taking more time, with the majority of participants seeing no difference in time between traditional and multiple article dissertation formats.

\section{Current practices}

Of the 12 institutions surveyed, $100 \%$ offered traditional dissertation formats. In addition, five institutions offered the multiple article format, and three offered a hybrid format (see Table 1). Of the seven institutions that only offered traditional dissertation formats, three institutions reported that they had discussed alternative culminating projects, while four institutions had not. These data indicate that the field of instructional technology is moving in the direction of offering alternative culminating projects.

As alternative culminating projects become more prevalent in instructional technology, current practices will become more valuable to institutions still considering this transition. Leaders of institutions who offered multiple article dissertation formats identified the following current practices for implementation of the multiple article format.

\section{Structure}

Although institutions varied in the number of required articles for the multiple article format, three out of five institutions reported that they required three journal-ready articles. In addition, the institutions that had specific requirements for the dissertation's structure required $\mathrm{PhD}$ candidates to include a summary of all their articles at the end of the dissertation. This requires $\mathrm{PhD}$ candidates to connect their articles in a way that more closely resembles the traditional dissertation.

\section{Authorship}

Three out of five institutions allowed articles in multiple article format dissertations to include co-authors, as long as the $\mathrm{PhD}$ candidate is the first author in all the studies. No institutions indicated that they do not allow faculty co-authorship on articles. However, only one institution said that they would allow student co-authors as part of a student's dissertation.

\section{Role of the committee and defence}

Since multiple article dissertations can be published prior to the dissertation defence, some question the role of the committee and defence because the articles have already been accepted as publishable by reviewers and thus completed works. Two institutions admitted that their institution is still working on defining the role of the committee and defence if articles have been accepted for publication. However, one institution claimed that it is best to not let publication acceptance interfere with the defense. They said, "The institution does not accept the decision of an editorial review board for its decision about conferring a degree. If the article 'misses the mark,' the committee will ask for and expect revisions to satisfy institutional and committee requirements."

\section{Quality}

As mentioned earlier, four institutions (80\%) had not set concrete expectations for quality of articles in multiple article dissertations. Additionally, four institutions did not require dissertation articles to be published in a certain tier of journal. More research is needed to ascertain if there are current practices concerning quality assessment in multiple article dissertations.

\section{Moving forward}

As more institutions adopt alternative culminating projects, 10 department representatives recommended that dissertation formats be tailored to students' goals. For example, five department representatives recommended a multiple article format for students going into academia, but recommended a traditional or hybrid approach for pre-practitioners. One department representative said, "For students intending to pursue a career in academia, I would highly encourage writing the manuscripts option. For students intending to pursue applied employment (not related to research or the need for publications), I would encourage the traditional approach." Similarly, two representatives saw a hybrid approach as "a great middle ground" between the traditional format 
and multiple article format. As current practices for alternative culminating projects are discussed and considered, department representatives recommended student goals remain in the forefront of the conversation.

\section{Discussion}

The results of this study have the potential to influence instructional technology as a field, as well as future research regarding alternative culminating projects.

\section{Implications for instructional technology}

Many of our findings are consistent with the literature on the benefits and challenges of multiple article dissertation formats. The following are areas in which our findings support and add to the current literature on the multiple article format, with a specific focus in the discipline of instructional technology.

\section{Publication and dissemination}

Research has suggested that most dissertations never get published (De Jong et al., 2005; McPhie, 1960; Robinson \& Dracup, 2008) and that completing multiple article dissertation formats can lead to increased publication and impact. However, prior to this study, no data were taken regarding the field of instructional technology in particular. In congruence with the literature, our findings show that many instructional technology dissertations never get published (57\% of our sample) and that completing an alternative culminating project can increase the likelihood of publication, and therefore increase the dissemination and impact, of dissertation research. This quantitative data support the claim that multiple article dissertation formats may increase the impact of dissertations in the field.

\section{Authenticity}

In general, the literature supported the assertion that alternative culminating projects can give students authentic experience in writing for journals outside the institution (Duke \& Beck, 1999; Hartley \& Betts, 2009; Hill et al., 2011; McPhie, 1960; Morris \& Tipples, 1998; Robinson \& Dracup, 2008; Walkington, 2008) and in the publication process (Robinson \& Dracup, 2008; Walkington \& Jenkins, 2008). Additionally, literature outside of instructional technology suggests that having publications could increase employment options (De Jong et al., 2005; Hartley \& Betts, 2009; McPhie, 1960; Robinson \& Dracup, 2008; Walkington, 2008) and jump-start a research agenda (De Jong et al., 2005; Morris \& Tipples, 1998). Our research is congruent with these findings, with one exception. Although many students and alumni thought that publishing during graduate school could help them obtain jobs in academia, others worried that potential employers might look down on the multiple article format. This discrepancy shows that students and alumni in instructional technology value the experience and practice of writing journal articles, but perceive a lack of acceptance that to some may override the benefits to authenticity that the multiple article format can provide.

\section{Rigor}

Even though respondents generally perceived multiple article formats to be more work, a common perception among alumni was that multiple article formats lessen the rigor involved in the dissertation. They argued that the nature of the multiple article format broadens the scope of inquiry, which leads to a loss in depth. This perception could be why instructional technology has had a hard time fully accepting the format as a field.

If instructional technology is to continue to offer and implement multiple article dissertation formats, the perception that multiple article formats lack rigor needs to be resolved. Since the majority (80\%) of institutions surveyed didn't have specific expectations for quality of multiple article formats, there is an opportunity to improve the quality of multiple article dissertations while resolving the perception that multiple article dissertations lack rigor and depth. If institutions establish specific criteria for multiple article dissertations, such as guidelines for how the articles should relate and form a coherent research agenda and specific ways that candidates can demonstrate depth of understanding, then those in the field might perceive multiple article dissertations to be more rigorous. Additionally, we propose that organisations like AECT, Australasian Society for Computers in Learning in Tertiary Education (ASCILITE), International Council for K-12 Online Learning 
(INACOL) and other major organisations in the field consider promoting multiple article dissertation formats for universities in their organisation, in order to propel the rigor of such dissertations forward. Similar to how AECT (2014) has created an official document about expectations for tenure and promotion, an organisation could create official policy positions concerning the completion and mentoring of multiple article dissertation formats. These policies could inform students and advisors completing multiple article formats, as well as provide a clear guide for quality and rigor.

\section{Study limitations and implications for future research}

This study, while providing useful initial insight into perceptions surrounding multiple article dissertation formats, did suffer from a few limitations. These include a small sample size of respondents that mostly represented the view of North American universities. Also, because we wanted to provide anonymity to participants speaking on behalf of their departments, we weren't able to track what kinds of institutions the respondents were from and how they mentor and advise article format dissertations.

Although this research identified many perceptions of multiple article dissertation formats, it also identified gaps that call for further research on the topic. The following are areas that future research needs to address in order to fully understand the benefits, challenges, and current practices of multiple article formats in instructional technology.

\section{Collaboration}

Alumni who completed alternative culminating projects reported that their dissertations led to collaboration with advisors and committee members after the defense. However, further research is needed to understand the extent and circumstances of this collaboration. Additionally, research is needed to see if multiple article dissertation formats can increase collaboration with others besides the committee, such as peers and faculty outside of the student's institution, and how this affects overall faculty advising workloads and student experiences.

\section{Acceptance}

Our research found that students, alumni, and department representatives perceived a lack of acceptance surrounding multiple article dissertation formats. In particular, students and alumni worried that employers might look down on multiple article dissertation formats, and some department representatives found that some of their colleagues were opposed to implementing alternative culminating projects. Although the literature suggests that some professionals may be opposed to the change for the sake of tradition (Tronsgard, 1963), other concerns of alternative culminating projects were cited, such as an ambiguity of requirements and an unclear view of the role of the committee and defense. These uncertainties in quality may contribute to a perceived lack of rigor surrounding multiple article formats, and could be remedied through clearer policy documents outlying multiple article dissertation expectations. Further research is needed to see if an improved definition of quality and practice for multiple article dissertations could increase acceptance of the multiple article format in instructional technology.

\section{Preparation}

Students and alumni perceived that writing articles during graduate school could prepare PhDs for a career in academia. Specifically, respondents felt that having publications could help graduates obtain employment, and jump-start their careers. However, further research could look at the effects of multiple article dissertation formats, and follow students' job searches and career paths, in order to look more specifically at the long-term benefits and challenges of multiple article formats.

\section{Mentoring}

Further research is needed to understand current practices in mentoring multiple article dissertation formats. Since department representatives recommended that alternative culminating projects be tailored to students' goals, strategies for mentoring alternative culminating projects may differ from strategies for mentoring traditional formats. Additionally, the amount of mentoring required for multiple article dissertations could be studied further. Even though the majority (66\%) of the participants in our study felt that they received the same 
amount of mentoring completing an alternative culminating project as they would have doing a traditional format, our research did not look into the perceptions of advisors of alternative culminating projects. Further research could delve into the experience of alternative culminating projects from a mentor's viewpoint, and get at the struggles of mentoring alternative culminating projects, the time involved, and current practices.

\section{Conclusion}

As the culminating experience that determines whether or not a doctorate degree is awarded, a dissertation should reflect a student's interests and goals in a way that can prepare a $\mathrm{PhD}$ for a lifetime of discovery and scientific writing. Relevant and rigorous, a dissertation of quality can transform a student into a scholar while advancing understanding in the field. For some, alternative culminating projects may increase both the authenticity and influence of the dissertation experience.

In this study, we investigated perceptions and current practices of multiple article dissertation formats through qualitative methods, descriptive statistics, and inferential statistics. We found that multiple article dissertation formats have the potential to increase publication and dissemination, and are perceived to be more authentic in regards to writing process, collaborative work, and preparation for an academic career. In addition, we found a perceived lack of acceptance and rigor regarding alternative culminating projects, possibly because most institutions lack clearly defined expectations for quality and practice. As current practices develop and emerge, multiple article dissertation formats could become an effective way to help students become engaged in authentic scholarship practices that can benefit them and further knowledge in the field.

\section{References}

Association for Educational Communications and Technology. (2014). The AECT tenure and promotion $(T \& P)$ guide. Bloomington, IN: Author. Retrieved from https://c.ymcdn.com/sites/aect.siteym.com/resource/collection/AD6CAA0B-8342-40E4-AB23641A7078802B/The_AECT_Tenure_and_Promotion_Guide-v12.pdf

Anglin, G. J. (1995). Instructional technology: Past, present, and future. Englewood, CO: Libraries Unlimited.

Archbald, D. (2010). "Breaking the mold" in the dissertation: Implementing a problem-based, decisionoriented thesis project. Journal of Continuing Higher Education, 58(2), 99-107. doi:10.1080/07377361003617368

Baggs, J. G. (2011). The dissertation manuscript option, Internet posting, and publication. Research in Nursing \& Health, 34(2), 89-90. doi:10.1002/nur.20420

Berelson, B. (1960). Graduate education in the United States. New York, NY: McGraw-Hill.

Boeckmann, M. E., \& Porter, A. L. (1982). The doctoral dissertation in the biosciences. BioScience, 32(4), 272-277. doi:10.2307/1308534

Boote, D. N., \& Beile, P. (2005). Scholars before researchers: On the centrality of the dissertation literature review in research preparation. Educational Researcher, 34(6), 3-15. doi:10.3102/0013189X034006003

Breimer, D. D., Janssen, A. A. M., \& Damen, J. C. M. (2005). Hora est!: On dissertations. Leiden: Universiteitsbibliotheek.

Calabrese, R. L. (2006). The elements of an effective dissertation and thesis. A step-by-step guide to getting it right the first time. Lanham, MD: Rowman and Littlefield Education.

Charlesworth, S. M., \& Foster, I. D. (1996). 'Water and environmental systems': Achieving student-centred learning objectives with an undergraduate journal. Journal of Geography in Higher Education, 20(1), 4554. doi:10.1080/03098269608709344

De Jong, M .J., Moser, D. K., \& Hall, L. A. (2005). The manuscript option dissertation: Multiple perspectives. Nurse Author \& Editor, 15(3), 7-9.

Duke, N. K., \& Beck, S. W. (1999). Education should consider alternative formats for the dissertation. Educational Researcher, 28(3), 31-36. doi:10.3102/0013189X028003031

Evans, T., Macauley, P., Pearson, M., \& Tregenza, K. (2009). A decadic review of PhDs in Australia. In P. Jeffrey (Ed.), Proceedings of the Joint AARE/NZARE 2003 Conference (pp. 1-15). Melbourne: Australian 
Association for Research in Education. Retrieved from http://www.aare.edu.au/data/publications/2003/eva03090.pdf

Fiegener, M. K. (2010, November). Numbers of doctorates awarded continue to grow in 2009; indicators of employment outcomes mixed. InfoBrief. Arlington, VA: National Science Foundation. Retrieved from ERIC database. (ED513342)

Fox, E. A., McMillan, G., \& Eaton, J. L. (1999). The evolving genre of electronic theses and dissertations. In Proceedings of the 32nd Annual Hawaii International Conference (pp. 1-20). doi:10.1109/HICSS.1999.772646

Gilman, D.A. (1974). The dissertation as a terminal exercise in scholarly activity. Contemporary Education, 45, 309-312. Retrieved from ERIC database. (EJ104956)

Gross, D., Alhusen, J., \& Jennings, B. M. (2012). Authorship ethics with the dissertation manuscript option. Research in Nursing \& Health, 35(5), 431-434. doi:10.1002/nur.21500

Hartley, J., \& Betts, L. (2009). Publishing before the thesis: 58 postgraduate views. Higher Education Review, 41(3), 29-44.

Hill, J., Kneale, P., Nicholson, D., Waddington, S., \& Ray, W. (2011). Re-framing the geography dissertation: A consideration of the alternative, innovative, and creative approaches. Journal of Geography in Higher Education, 35(3), 331-349. doi:10.1080/03098265.2011.563381

Isaac, P D., Quinlan, S. V., \& Walker, M. W. (1992). Faculty perceptions of the doctoral dissertation. Journal of Higher Education, 63, 241-268. doi:10.2307/1982014

Johnson, R. B., \& Onwuegbuzie, A. J. (2004). Mixed methods research: A research paradigm whose time has come. Educational Researcher, 33(7), 14-26. doi:10.3102/0013189X033007014

Lee, A. (2010). When the article is the dissertation: Pedagogies for a Ph.D. by publication. In C. Aitchison, B. Kamler, \& A. Lee. (Eds.), Publishing pedagogies for the doctorate and beyond (pp. 12-29). New York, NY: Routledge.

Lincoln, Y. S. (1985). Naturalistic inquiry. Newbury Park, CA: Sage.

McClelland, C. E. (1980). State, society, and university in Germany, 1700-1914 (Vol. 240). Cambridge: Cambridge University Press.

McPhie, W.E. (1960). Factors affecting the value of dissertations. Social Education, 24(December), 375-377.

Monaghan, P. (1989). Some fields are reassessing the value of the traditional doctoral dissertation. The Chronicle of Higher Education, 35(29).

Morris, H. M., \& Tipples, G. (1998). Choosing to write a paper format thesis. The Journal of Nursing Education, 37(4), 173-175. doi:10.3928/0148-4834-19980401-08

Morse, J. M. (1991). Approaches to qualitative-quantitative methodological triangulation. Nursing Research, 40(2), 120-123. doi:10.1097/00006199-199103000-00014

Orey, M. (2013). Educational Media \& Technology Yearbook, 2012, Vol. 37. In Educational Media and Technology Yearbook (pp. 225-357). New York, NY: Springer. doi:10.1007/978-1-4614-4430-5_13

Reid, W. M. (1978). Will the future generations of biologists write a dissertation? BioScience, 28(10), 651654. doi:10.2307/1307396

Ritzhaupt, A. D., Sessums, C., \& Johnson, M. (2011, November). Where should educational technologists publish? An examination of journals within the field. Paper presented at the Association of Educational Communications and Technology, Jacksonville, Florida.

Robinson, S., \& Dracup, K. (2008). Innovative options for the doctoral dissertation in nursing. Nursing Outlook, 56(4), 174-178. doi:10.1016/j.outlook.2008.03.004

Saldaña, J. (2012). The coding manual for qualitative researchers (No. 14). Los Angeles, CA: Sage.

Seels, B., \& Richey, R. (1994). Instructional technology: The definition and domains of the field. Washington, DC: Association for Educational Communications and Technology.

Stemler, S. (2001). An overview of content analysis. Practical Assessment, Research \& Evaluation, 7(17). Retrieved from http://PAREonline.net/getvn.asp?v=7\&n=17

Thomas, J. R., Nelson, J. K., \& Magill, R. A. (1986). A case for an alternative format for the thesis/dissertation. Quest, 38(2), 116-124. doi:10.1080/00336297.1986.10483846

Thurgood, L., Golladay, M. J., \& Hill, S. T. (2006). U.S. doctorates in the 20th century (NSF 06-139). Arlington, VA: National Science Foundation. Retrieved from http://www.nsf.gov/statistics/nsf06319/ 
Tronsgard, D. T. (1963). A common-sense approach to the dissertation: Should the graduate schools take a fresh look at this traditional requirement? The Journal of Higher Education, 34(9), 491-495. doi:10.2307/1979204

Walkington, H. (2008). Geoverse: Piloting a national e-journal of undergraduate research in geography. Planet, 20, 41-46. doi:10.11120/plan.2008.00200041

Walkington, H., \& Jenkins, A. (2008). Embedding undergraduate research publication in the student learning experience. Brookes eJournal of Learning and Teaching, 2(3). Retrieved from http://bejlt.brookes.ac.uk/article/embedding_undergraduate_research_publication_in_the_student_learning experi/

West, R. E., \& Rich, P. J. (2012). Rigor, impact, and prestige: A proposed framework for evaluating scholarly publications. Innovative Higher Education, 37(5), 359-371. doi:10.1007/s10755-012-9214-3

Willis, J. W., Inman, D., \& Valenti, R. (2010). Completing a professional practice dissertation: A guide for doctoral students and faculty. Charlotte, NC: Information Age.

Wolfle, D., \& Kidd, C. V. (1971). The future market for Ph.D.’s. Science, 173(3999), 784-793. doi:10.1126/science.173.3999.784

Yoels, W. C. (1973). On the fate of the Ph.D. dissertation: A comparative examination of the physical and social sciences. Sociological Focus, 7(1), 1-13. doi:10.1080/00380237.1974.10570872

Corresponding author: Rebecca Arlene Thomas, beccathomas4777@gmail.com

Australasian Journal of Educational Technology (C) 2016.

Please cite as: Thomas, R.A., West, R.E., \& Rich, P. (2016). Benefits, challenges, and perceptions of the multiple article dissertation format in instructional technology. Australasian Journal of Educational Technology, 32(2), 82-98. 